\title{
Taxation students' perceptions of open-book assessment prior to the qualifying examination of South African chartered accountants
}

\author{
H du Preez* \\ Department of Economics and Management, University of Pretoria
}

CS du Preez

Department of Economics and Management, University of Pretoria

*Contact: Hanneke.dupreez@up.ac.za and carl@ksm.co.za

\begin{abstract}
In this study taxation students' perceptions of open-book assessment, prior to their exposure to open-book assessment in the qualifying examination of South African chartered accountants, is explored. A focus group was conducted using the Interactive Qualitative Analysis methodology. In this focus group, taxation students without prior exposure to open-book assessment identified their perception themes (also referred to as affinities) on open-book assessment. These affinities were grouped together and described by them as: good preparation, back-up, encouragement, general advantages, improved quality of answers, negative symptoms, negative environment, personal experience and hindrance, different approach and time management. The students then identified relationships between these different affinities. These relationships were summarized and reflected on a System Interrelationship Diagram, giving a visual map of the students' perceptions.
\end{abstract}

Findings from the System Interrelationship Diagram indicated that students perceive good preparation as the strongest driver for successful completion of an open-book assessment. This System Interrelationship Diagram showed three primary outcomes namely negative symptoms, different approach and time management. This implies that students perceived that open-book assessment may create laziness (negative symptom) in students leading to a different approach when preparing for and completing such assessments. Finally, they concluded that successful completion of an open-book assessment necessitates proper time management.

\section{KEY WORDS}

Open-book assessment; qualitative research, Interactive Qualitative Analysis, taxation, focus group, chartered accountant, perception, affinity, theme. 


\section{INTRODUCTION}

The regulation of the auditing and accounting professions has been fraught with problems. This can be seen in the high profile accounting cases in the United States of America (USA) like WorldCom in 2002 (Lavey, 2006) and Enron in 2001 (Thomas, 2002), when accounting loopholes were used to hide billions of dollars-worth of debt. Such incidents highlighted the shortcomings of the accounting profession; giving rise to questions regarding the regulation of these areas (Wikipedia, 2010). One of the areas which appeared to need attention was the process of becoming a chartered accountant. In South Africa, the Chartered Accountant Qualifying Examination Part One (QE Part 1) has been changed from a closed-book assessment to an open-book assessment. In this study the focus will be on an aspect of this change. The South African Institute of Chartered Accountants (SAICA) made this change to their assessment policy in 2004 (SAICA, 2005). SAICA's main objective for such an assessment policy change was to establish whether candidates were able to apply the prescribed concepts and principles to real-life situations (SAICA, 2005).

The motivation for this study is closely linked to fact that SAICA changed its assessment technique from a closed-book assessment to an open-book assessment. Baccalaureus Commercii (B Com) Accounting students at the University of Pretoria are only exposed to closed-book assessment during their undergraduate studies. Through informal discussions with students, it appears that their initial perceptions (ill-informed or not) of open-book assessment may have an indirect influence on their success in the QE Part 1. Therefore the bases for this study are grounded within the accounting profession and its attempt to improve the quality of its new members. Taxation is one of the four areas included in the curriculum and assessed in the QE Part 1. Although the students need to prepare for examinations in all four areas, taxation was chosen for this study -as a discussion of all four has the potential to draw the participants' focus away from open-book assessment to the differences between these four subject areas.

There is agreement in literature that open-book assessment creates a better understanding of the contents of a subject area (Baillie \& Toohey, 1997; Durham, 1990; Feller 1994; Theophilides \& Koutselini-Ioannidou, 2000). On the other hand, Boniface $(1985)^{1}$ contends that the possible use of notes, textbooks and/or other resources might discourage students from preparing thoroughly, as they will have all the relevant information at hand. When preparing for an assessment, students tend to take the type of assessment into consideration (Struyven, Dochy \& Janssens, 2002). Their perceptions of the specific assessment type might influence their attitude towards both preparing for the assessment and writing it (Struyven et al., 2002).

The purpose of this study is to understand students' perceptions of open-book assessments. The research was conducted at a time when the students have not been exposed to open-book assessments or gained any experience of it. These students were registered taxation students at the University of Pretoria (South Africa). The research question in this study is formulated as follows: What are taxation students' perceptions of open-book assessment, with specific emphasis on the open-book assessment of the QE Part 1 examination? According to the Interactive Qualitative Analysis (IQA) methodology, this research question is divided into the following sub-questions:

\footnotetext{
${ }^{1}$ In this study the researcher does not hesitate to incorporate older primary references. The authors of many recent publications continue to refer to this particular landmark study.
} 
- What perceptions of open-book assessment emerge from taxation students' responses?

- How do these emerging perceptions of open-book assessment relate to one another?

The value of this study lies in creating a better understanding of open-book assessment, specifically in relation to taxation students' perceptions. In a more practical sense, the findings of this study could be applied to improve the current preparation and assessment of taxation students before they write the QE Part 1.

The focus in this study is not on analysing the different types of open-book assessments nor on a specific type of open-book assessment. There will also not be a detailed discussion of SAICA's purpose with the open-book assessment. The purpose of this study is to understand taxation students' perceptions of open-book assessments.

\section{RESEARCH METHODOLOGY}

\section{Research design}

Interactive Qualitative Analysis (IQA) was chosen as research design. It is a qualitative method of research that attempts to incorporate and merge some of the disconnections in theorising about the purposes and methods of qualitative research, and also describes a detailed, application-orientated systematic process by which data, analysis and interpretation are merged into a whole (Northcut \& McCoy, 2004). IQA is anchored in the constructivist and interpretivist paradigm, together with a strong systems theory approach - the primary purpose of which is to represent the meaning of a phenomenon in terms of elements and the relationship amongst them (Creswell, 2003; Northcutt \& McCoy, 2004; Mampane \& Bouwer, 2011). An IQA focus group was mobilised. The students in the focus group were chosen at a stage in their postgraduate studies when they had not yet encountered (been exposed to or experienced) open-book assessment. Although the participants had not been exposed to or experienced open-book assessment, they might have been influenced by the experiences and opinions of other people and therefore formed their own perceptions. These perceptions (ill-informed or not) may drive their attitude, preparation and ultimately their success in the QE Part1. It is therefore vitally important firstly to identify these perceptions in order to know what must be addressed in order to enhance a student's success.

\section{Selection process}

In this study the focus group comprised of B Com Accounting (Honours) students at the University of Pretoria (South Africa) with taxation as one of their major subjects. The focus group consisted of 10 participants selected from 218 students enrolled for taxation as part of their B Com Accounting (Honours) degree. These students were preparing themselves for the QE Part 1 in the following year. The participants for the focus group were chosen by means of the complex probability sampling technique and then more specifically the systematic sampling type (Cooper \& Schindler, 2003).

The IQA method used in this study requires that the focus group has to consist of 10 15 individuals (Northcutt and McCoy, 2004). Further processes are built into this 
methodology to ensure that all selected participants are actively engaged in the process of constructing their unique understanding of open-book assessment.

\section{Data collection and analysis}

Data collection followed the formal process of the IQA developed by Northcutt and McCoy (2004). The classic IQA process includes a focus group followed by individual semi-structured interviews. In this study only an IQA focus group was utilised. The data was generated via a silent nominal phase, inductive coding (process of naming); deductive coding (process of reorganising) and theoretical coding (individually defining relationships). These inductive and deductive processes are described by John Dewey as the 'double movement of reflective thought' (Cooper \& Schindler, 2003; Northcutt \& McCoy, 2004). This is typically done in the IQA process during which data collection and analysis are part of the same process and where participants have full participation in drawing out themes/affinities and creating theory associated with the phenomenon being researched.

The IQA method is used to improve the understanding of new / emerging perceptions. The following process was followed: A focus group was created, consisting of participants that have something to say about the phenomenon, in this case open-book assessment. The question that was posed to the focus group through a facilitator was: "Tell me about your personal perceptions on open-book assessment". Then the focus group was given some time to write any perception/feeling/concept down on pieces of paper, one perception/feeling/concept per piece of paper. These pieces were then stuck up on the wall (silent nominal phase). Then participants were requested to sort the perceptions on these pieces of papers in themes or ideas. This continued until all the participants were satisfied with the groupings (inductive coding). This whole process was completed in total silence. After this part had been completed, the participants were asked to provide a name for each grouping. These names became the perception themes (affinities) as described in this paper (deductive coding) (Mampane \& Bouwer, 2011). All of above were needed to answer the first sub-question.

After the completion of the focus group, the participants individually defined the relationships between the different perception themes that were created by the focus group (theoretical coding). This process was done by completing an Affinity Relationship Table (ART) (Appendix 1), thus answering the second sub-question. This study is therefore clearly divided into two sections: firstly, the focus group that created the perception themes and secondly, individual focus group members who completed the ART.

When the perception themes (affinities) had been defined and the relationships between them stated, a System Influence Diagram (SID) could be constructed. This diagram symbolises a mind map based on the relationships generated among the perception themes by each focus group member (Mampane \& Bouwer, 2011). This is done by utilising the Pareto principle. Northcutt \& McCoy (2004) suggest that the use of the Pareto principle ${ }^{2}$ will yield an acceptable group composite for the focus group. This principle is frequently used by management and systems theorists, who refer to it as the

\footnotetext{
2 The Pareto Principle is named after the nineteenth century economist Wilfredo Pareto (1843-1913) and states that "something like $20 \%$ of the variables in a system will account for $80 \%$ of the total variation in outcomes".
} 
'trivial many and the significant few principle'. This is a specific reference to the idea that $20 \%$ of the variables in a system will account for $80 \%$ of the total variation in the outcomes of that system (Northcutt \& McCoy, 2004). Essentially, this means that the minority of relationships in any system will account for the majority of disparities in that system. IQA uses the Pareto rule of thumb to reach consensus within the group and to indicate which of the affinity pairs should be included in the group Interrelationship Diagram (IRD). This IRD is a matrix containing the affinity pairs or relationships in the system. Through the process of indexing the degree of optimisation in the system, perception themes are sorted as drivers (elements that can be seen as the fundamental causes/ sources of influence on perception themes in a system) or outcomes (significant effects caused by many of the perception themes in a system) in order to draw the SID; first drawing a cluttered SID, then organising it and lastly uncluttering it (Northcutt \& McCoy, 2004). This uncluttered SID is created through the process of eliminating all the relationships that can possibly be substituted with another pathway on the diagram and presenting it visually.

\section{LITERATURE REVIEW}

Some of the earliest research done on open-book assessment was undertaken in 1951 in the USA amongst high school students. For the next 27 years, relatively little research was done in this field. During this period examination questions seem not to have been specifically designed for the open-book assessment technique (Francis, 1982). Most of the assessment techniques used in research projects can be classified as traditional, including multiple-choice questionnaires, short questions and essay questions. The skills tested in the majority of the research carried out during this period were classified mainly as focusing on the acquisition of factual knowledge. This leads to the conclusion that in most of the projects, the full potential of open-book assessment was not used, for example, allowing students to apply their knowledge creatively (Feller 1994). This still tends to be the case, although in more and more research on open-book assessment it is regarded as a tool and technique for simulating real-life situations (Broyles, Cyr \& Korsen, 2005; Heijne-Penninga, Kuks, Schonrock-Adema, Snijders, \& CohenSchotanus, 2006).

Currently, open-book assessment is seen as one of the alternative assessment types that include assessment requiring students to generate their own responses rather than choosing or taking a response from a given list or text (Jackson, Watty, Yu \& Lowe, 2006). Open-book assessment allows students to make use of different materials during the assessment process (Theophilides \& Koutselini-Ioannidou, 2000). This material may include textbooks, lecture notes and dictionaries, but students are not allowed to elicit answers directly or indirectly from fellow students (Kalish, 1958). This would imply that students must be able to mobilise the knowledge and skills they have acquired during their studies to unravel problems, using the available resources (Lancaster, 2006).

Some researchers believe that making use of open-book assessment will deliver future students who can think independently and creatively, and who are able to process information analytically (SohLoi \& Yaun, 1998). Koutselini-Ioannidou (1997) also contributed by reasoning that open-book assessment tends to provide a higher level of study motivation. Study motivation for open-book assessment is shown to be influenced by three possible factors: the teaching-learning process, the student's expectations of 
the assessment and finally the student's ability to use the allowed books and materials during the assessment.

For purposes of this study, open-book assessment will be defined as an assessment type during which the student has access to various supporting resources during an assessment situation. However, the only supporting documents allowed into the QE Part 1 assessment are specific prescribed resources, including the SAICA handbook and the SAICA legislation handbook (SAICA, 2009). Wadee (2010) noted that this change was essential if the Chartered Accountant (South Africa) ${ }^{3}$ designation was to remain relevant and growing. Wadee (2010) stated that the latest changes were designed to enhance the quality and status of future CA (SA)'s by including broad-based soft skills and general business skills.

\section{RESULTS AND DISCUSSION}

In the following two sub-sections the descriptions of the perception themes (affinities) according to the focus group will be outlined, followed by the relationships between the different affinities, as indicated by the focus group participants.

\section{What perceptions of open-book assessment emerge from taxation students' responses?}

The results of the different perception themes (affinities) identified during this study will follow, together with an integrated discussion of each.

\section{Good preparation (Affinity 1)}

According to the focus group, this affinity emphasised the importance of Taxation knowledge acquired before attempting the open-book examination. They considered understanding the principles of the Income Tax Act rather than the theory to be one of the most important aspects of preparation. They thought that familiarising themselves with the layout of the Income Tax Act was a necessary tool in open-book assessment, while forming a constant referencing habit would also help them to be well prepared for the examination.

\section{Discussion on the affinity 'Good preparation'}

The focus group identified the importance of taxation knowledge when preparing for open-book assessment, but more specifically principles of taxation rather than theory. Various researchers confirm that a strong focus on principles tends to nurture a better understanding (Killen \& Hattingh, 2004; Theophilides \& Koutselini-Ioannidou, 2000). This aspect of open-book assessment set the stage for students to move from surface learning to deep learning (Brightwell, Daniel \& Stewart, 2004; Feldhusen, 1961; Gray, 1993; Heijne-Penninga et al,. 2006). The focus group suggested that when preparing for open-book assessment, the layout of the textbook should be studied and arranged by using markers, flags and highlights. The importance of preparing the material in this way is confirmed by the findings by Broyles et al. (2005). When it comes to the positive effects of the referencing habit, research has shown that maintaining a referencing habit while preparing for an open-book assessment is essential, but during an open-book assessment it should be used sparingly, and only as a back-up (Boniface, 1985; Jacobs,

${ }^{3} \mathrm{CA}(\mathrm{SA})$ is the official designation for a registered chartered accountant in South Africa. 
1990). It was also found that the time spent on referencing material during the openbook assessment correlated negatively with the students' final marks, in fact, it was demonstrated that time spent on referencing often resulted in incomplete answers (Boniface, 1985; Jacobs, 1990). eHow Education (2009) provides advice specifically on methods that enhance quick referencing when it becomes necessary during open-book assessment with the use of index cards, brief notes and the layout of the textbook. The availability of such resources resonates with Lancaster's (2006) idea that the knowledge and skills acquired during studies, along with resources, must be available to students during assessment to help unravel problems.

\section{Back-up (Affinity 2)}

According to the focus group, this affinity describes the positive feeling that there is a last resort in a taxation examination. They felt that the Income Tax Act could be used as reference to help eliminate different options and to find the correct wording. They concluded that access to additional detail in the Income Tax Act could even lead to extra marks being awarded.

\section{Discussion on the affinity 'Back-up'}

The focus group referred to the availability of resources as a last resort. This resonates with March's (1980) argument that open-book assessment allows students to access resources that will help them present evidence of their ability. The focus group maintained that, a student who had access to information could score extra marks, but, on the other hand, the student could also include irrelevant information in the solution. Broyles et al. (2005) concurred when they advised against the use of available materials to confirm every answer, and advised that this should be done only when necessary.

\section{Encouragement (Affinity 3)}

According to the focus group, this affinity indicates that the idea of writing an openbook assessment can make students feel more optimistic. They also felt that taxation students may feel more motivated when confronted with an open-book situation.

\section{Discussion on the affinity 'Encouragement'}

The focus group described the open-book assessment as making the students feel optimistic. A multitude of studies give evidence that students appear to have an optimistic orientation towards open-book assessment (Brightwell et al., 2004; Feldhusen, 1961; Feller, 1994; Gray, 1993; Theophilides \& Koutselini-Ioannidou, 2000). Theophilides and Dionysiou (1996) found that students perceived open-book assessment as more positive than closed-book assessment. When referring to optimistic orientations and positive perceptions, it must be noted that in a vast number of studies it is shown that open-book assessment is associated with lower student anxiety levels in comparison with closed-book assessment (Feller, 1994; Jacobs, 1990; Theophilides \& Dionysiou, 1996). More specifically, the work of Theophilides and Koutselini-Ioannidou (2000) found that examination anxiety and feelings of pressure seemed to decrease during openbook assessment. 


\section{General advantage (Affinity 4)}

According to the focus group, the Income Tax Act used in open-book assessment is a visual tool for accessing detail. They pointed out that the problem of the frequentlychanging taxation laws could be surmounted if the changed information were available in Income Tax Act. This could help students avoid having to memorise the technical information overload in taxation relating to definitions, rules, sections and formulae in the Income Tax Act, as well as lists of exemptions in other Acts.

\section{Discussion on the affinity 'General advantage'}

The focus group compared the availability of the textbook to a visual tool for accessing memorised detail. Further they felt that with the textbooks available they could bypass having to memorise the technical information overload in taxation studies. This is confirmed and reiterated by various research studies (Boniface, 1985; Broyles et al., 2005; Feldhusen, 1961; Jacobs, 1990). From the didactical perspective, numerous researchers have concluded that, when students understand the content, proficiency and professional skills are more easily attained (Brightwell et al., 2004; Feldhusen, 1961; Gray, 1993; Jacobs, 1990). This aspect of open-book assessment also sets the stage for students to progress from surface learning to deep learning (Botha, Fourie \& Geyser, 2005; Feldhusen, 1961; Gray, 1993; Heijne-Penninga et al., 2006). The problem of the continually-changing Income Tax Act was overcome by allowing students access to the Act itself during an assessment. Taking the textbooks in with them and having access to the most recent Income Tax Act was already recommended by Bowman in 1994.

\section{Improved quality of answers (Affinity 5)}

According to the focus group, this affinity suggests that having the Income Tax Act available allows students access to more detail than could be memorised. They considered that answers given by students would be more reliable and better expressed on account of the detail in the Income Tax Act available during the examination.

\section{Discussion on the affinity 'Improved quality of answers'}

The focus group stated that the textbooks offered more detail than the amount of information that could be memorised. A great deal of research does conclude that openbook assessment seems to improve the quality of students' answers (Botha et al., 2005; Mohanan, 1997; Struyven et al., 2002; Weber, McBee, \& Krebs, 1983). On the other hand, some research emphasises that, if the resources are used too extensively during the assessment, answers are often incomplete and poorly structured (Boniface, 1985; Jacobs, 1990). Research by Francis (1982) confirms that the availability of information does lead to a better structure and more acceptable solutions to the problems posed during the assessment. However, time is a constraint when searching the textbooks for appropriate answers. Boniface (1985), and later Jacobs (1990), found that time constraints in referring to the textbooks in an open-book assessment may lead to weaker solutions.

\section{Negative symptoms of open-book assessment (Affinity 6)}

According to the focus group, this affinity emphasises the time-consuming nature of preparing the Income Tax Act for the examination, as well as the process of understanding and practising by the students themselves. They pointed out that allowing 
students to take information into the examination could encourage students to become lazy.

\section{Discussion on the affinity 'Negative symptoms of open-book assessment'}

The focus group were of the opinion that preparing textbooks was time-consuming. Boniface (1985) found the same, especially in relation to the preparation phase for an open-book assessment, together with deciding what to study and what to take into the assessment, which may also waste valuable time. Students appear to believe that because textbooks are available during the assessment, they do not need to study so intensely (Feller, 1994). Some research shows that certain students prefer to copy answers directly from the textbooks, confirming their dependency on the textbooks (Clift \& Imrie, 1981; Koutselini-Ioannidou, 1997). The focus group went further and believed that students were liable to become lazy while preparing for an open-book assessment. Koutselini-Ioannidou (1997) and Lancaster (2006) point out that open-book assessment encourages laziness, especially when students realise that they can copy answers directly from the resources. Apart from research noting the possible waste of time, dependency on textbooks and nurturing laziness that may occur in an open-book assessment, many researchers report that students tend to study less for such a test. This has been shown to be accurate, especially when less time is spent on preparation, in comparison with a closed-book assessment (Boniface, 1985; Fellar, 1994; Jacobs, 1990; Theophilides \& Koutselini-Ioannidou, 2000). Theophilides and Koutselini-Ioannidou (2000) found that, overall; students tend to underestimate open-book assessment. They study less, either because they think an open-book assessment is easier (Clift \& Imrie, 1981) or because they believe that it is easy to find the answer in the available resources (Koutselini-Ioannidou, 1997).

\section{Negative environment (Affinity 7)}

According to the focus group, this affinity relates to the participants' perception of the situation in the examination hall. They anticipated that during the open-book assessment students will tend to page through the Income Tax Act, causing chaos and disruption.

\section{Discussion on the affinity 'Negative environment'}

There are distractions inside the examination hall, such as students paging through the Income Tax Act and dropping it on the floor. The focus group anticipated that this may promote chaos and disruption. No literature could be found to confirm that distractions are disruptive or have a negative effect on students attempting an open-book assessment.

\section{Personal experience and hindrance (Affinity 8)}

According to the focus group, this affinity relates to the feeling that open-book assessment adds no value to the learning process, and that it can even result in a inferior self-esteem. They mentioned that this assessment technique could be perceived as more difficult and demanding. They felt that the availability of the Income Tax Act could lead to excessive checking of answers and unnecessary wasting of time. However, they observed that, as far as having the Income Tax Act available is concerned, it could be helpful, because the Income Tax Act is difficult to understand and the expression is rather tortuous. 


\section{Discussion on the affinity 'Personal experience and hindrance'}

The focus group felt that open-book assessment added no value to the learning process, but it could cause lowered self-esteem. They said that using the Income Tax Act encouraged excessive checking. Van Tonder (1988) believes that educating students on open-book assessment and the ability to use the material before and during an assessment saves time and increases confidence during the assessment. Birenbaum and Feldman (1998) show that students' attitudes play a role in how they complete assignments and in the quality of learning exhibited, so engaging with students in this sense may be important. Boniface (1985) and Jacobs (1990) found that the more time was devoted to referencing and checking during an assessment, the lower the final marks tended to be (negative correlation). The focus group perceived open-book assessment as more difficult and demanding than a closed-book assessment. Brightwell et al. (2004) found that students still preferred open-book to closed-book assessment, even though they knew that open-book assessment required them to demonstrate higher-order thinking skills.

\section{Different approach (Affinity 9)}

According to the focus group, this affinity can be described as the mental and emotional change that follows when preparing for open-book assessment in comparison with closed-book assessment. They did point out that a proper open-book assessment preparation and examination technique must be developed and that study techniques had to be adjusted accordingly.

\section{Discussion on the affinity 'Different approach'}

The focus group expressed the view that a different study and examination technique was required when preparing for and writing an open-book assessment. Both Theophilides and Koutselini-Ioannidou (2000) and Chalmers and Fuller (1996) confirm that different assessment techniques require different study behaviour and examination techniques. Killen and Hattingh (2004) believe that a mind-shift is needed when changing to an open-book assessment, in which understanding, creativity, diversity and challenging the norm are emphasised. This position shows an inclination towards changing to open-book assessment by moving from surface learning to deep learning (Botha et al., 2005; Feldhusen, 1961; Gray, 1993; Heijne-Penninga et al., 2006). They all contend that it is important that textbooks be prepared for use during the assessment. This confirms exactly what eHow Education (2009) proposed.

\section{Time management (Affinity 10)}

According to the focus group, this affinity indicates that success when writing an openbook examination is dependent on effective time planning, proper study and examination technique and the realisation that the Income Tax Act available should be used only if absolutely necessary.

\section{Discussion on the affinity 'Time management'}

The focus group stated that time management was the essential factor in writing a successful open-book assessment. Broyles et al. (2005) concur by stating that being aware of time is vitally important. Time plays a role during preparation, while writing the assessment and when using the textbooks (tools) available during the assessment. Time management during the assessment is crucial to success (Boniface, 1985; Jacobs, 1990). 


\section{How do these emerging perceptions of open-book assessment relate to one another?}

The results of the study on relationships between the different perception themes (affinities) will be presented, followed by a discussion of these results.

\section{Results of the study on the relationships between different perception themes}

A document was compiled containing a list of the affinities and the participants' descriptions of them. Each participant in the focus group received this document, either in hard copy or via e-mail. Each participant was required to indicate whether there was a relationship between any two affinities and to indicate the nature of the relationship. The IQA calls this the simple Affinity Relationship Table (ART) (Appendix 1) for each participant (Northcutt \& McCoy, 2004). In other words, the participant had to decide which affinity of every two was the most influential. The participants were also asked to include a brief explanation of the relationship, using their own experiences and perceptions, the so-called 'if/then' statements, to complete a more detailed ART. The completed detailed ART-document was returned to the researcher, who used the information to compile a summarised ART for the focus group as a whole (Northcutt \& McCoy, 2004). The summarised ART was compiled to obtain the focus group's combined perception on the phenomenon.

The System Influence Diagram (SID) symbolises a mind map based on the relationships generated from the perception themes by each focus group member (Northcutt \& McCoy, 2004). The SID is a diagram drawn by using a group Interrelationship Diagram (IRD). The IRD is a matrix containing the affinity pairs or relationships in the system and therefore summarises all the theoretical codes in the system. Theoretical coding refers to all the possible influences or relationships between the affinities in a system, referring here to the affinities that evolved in the deductive and axial coding process that took place during the focus group session. For the focus group, the group IRD reflects the results of the group summarized ART (Northcutt \& McCoy, 2004).

After applying the Pareto protocol and the Pareto rule of thumb, the degree of optimism in the system is reflected in the power column of Table 2 (Appendix 2). In this study the power reaches a maximum at affinity pair number 35 . This indicates that 35 relationships account for $83.4 \%$ of the variation in the system. The first 35 affinity pairs are thus included in the group IRD.

In the group IRD (Table 3 - Appendix 3), the arrows show which affinity is influenced by which, e.g. Affinity 5 is influenced $(\leftarrow)$ by Affinity 3 , and Affinity 5 influences $(\uparrow)$ Affinities 1, 4, 6 and 10. Thus, Affinity 5 operated 4 times as a driver (as shown in the 'out' column) and was once an outcome (as shown in the 'in' column). Delta $(\Delta)$ represents the difference between the 'out' and 'in' totals in their respective rows.

All the affinities with positive delta numbers (Affinities 1, 5, 2, 3 and 7) are seen as drivers and all the affinities with negative delta numbers (Affinities 4, 6, 9 and 10) are seen as outcomes. An affinity where the 'out' and 'in' columns are equal, yielding a zero delta, are seen as a circular or pivot (Affinity 8). A further refining of the affinities can be found when looking at the 'out' or 'in' column with a zero value. An affinity containing a zero value in the 'out' column is classified as a primary outcome and an 
affinity with the 'in' column containing a zero value is classified as a primary driver. The classification of the affinities is summarised as tentative SID assignments in Figure 1.

\begin{tabular}{|c|c|}
\hline *Affinity & Assignment \\
\hline 1 & Secondary driver \\
\hline 5 & Secondary driver \\
\hline 2 & Secondary driver \\
\hline 3 & Secondary driver \\
\hline 7 & Secondary driver \\
\hline 8 & Circulator/ pivot \\
\hline 4 & Secondary outcome \\
\hline 6 & Primary outcome \\
\hline 9 & Primary outcome \\
\hline 10 & Primary outcome \\
\hline
\end{tabular}

Figure 1: Tentative SID assignments: Focus group

*Affinities: 1-Good preparation, 2-Back-up, 3-Encouragement, 4-General advantages,

5 -Improve quality of answers,

6-Negative symptoms, 7-Environment, 8-Personal experience and hindrance, 9-

Different approach, 10-Time management

At this stage in the analysis, the data is ready to be utilised in a SID. When drawing the SID, the drivers should be allocated on the left hand side and the outcomes on the right hand side with the primary drivers and primary outcomes furthest from one another. The secondary drivers and outcomes must be allocated between the primary drivers and secondary drivers with the circulator or pivot in the middle. Affinities with the same status must be sorted vertically. The relationships are summarised on the IRD. For every relationship between two affinities, an arrow should be drawn indicating the relationship as well as the direction of influence. A completed cluttered SID (Diagram 1 ) is drawn utilising the information from the IRD (Table 3). The purpose of this stage is to deliver a diagram that represents all the relationships of the system. When there are more affinities with a resulting increase in relationships, this SID can become of no real value as it is too complex to draw any conclusions from (Northcutt and McCoy, 2004). 


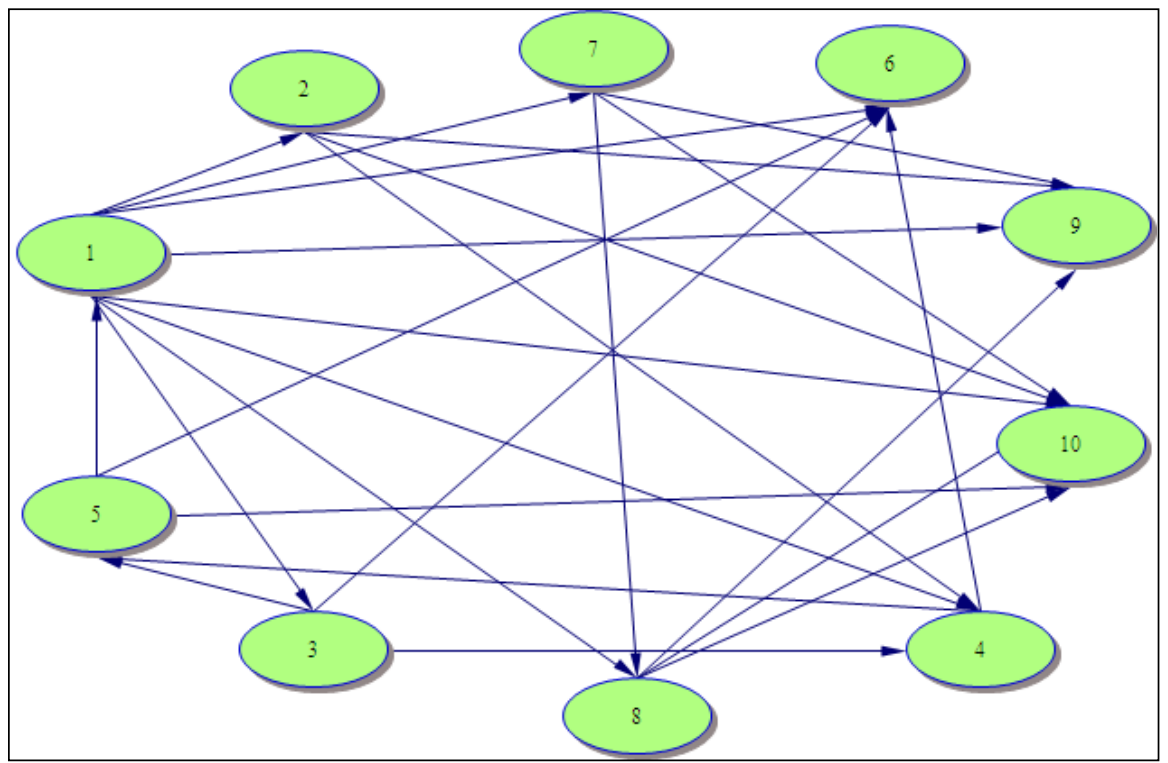

Diagram 1: Cluttered SID for focus group

*Affinities: 1-Good preparation, 2-Back-up, 3-Encouragement, 4-General advantages,

5-Improve quality of answers,

6-Negative symptoms, 7-Environment, 8-Personal experience and hindrance, 9-

Different approach, 10-Time management

It is therefore essential that the SID must be uncluttered. This is done by eliminating all possible relationships that can be substituted with another pathway on the diagram. This process of uncluttering will continue until all redundant relationships are deleted. (Northcutt and McCoy, 2004). Diagram 2 (the final uncluttered SID) shows the focus group's perceptions (described as affinities) on open-book assessment and their interaction with one-another. Thus, this final SID represents the students' perception model prior to experiencing open-book assessment.

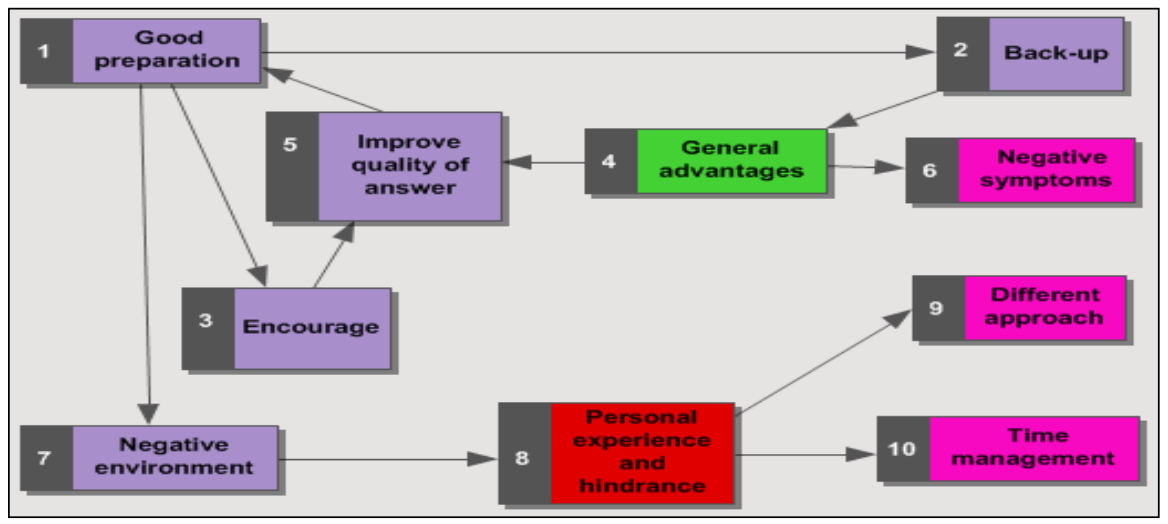

Diagram 2: Final uncluttered SID for focus group 
The relationships between the various affinities generated by the focus group are visually represented in the final SID (Diagram 2). Although it shows that there is no primary driver (refer to Figure 1), the affinity with the highest positive delta is good preparation, which functions as a secondary driver. The primary outcomes identified by the focus group were time management, negative symptoms of open-book assessment and different approach, as these have no impact on other affinities. Two feedback loops are present in this system and they revolve around good preparation. These feedback loops are interactive and influence each other.

The first feedback loop (Diagram 3) is named: More successful answering. In this feedback loop, good preparation is seen to be the strongest driver. There was a perception that a student who is well prepared for an open-book assessment has more effective access to the resources allowed into the assessment venue. If these resources are prepared before the assessment, they can be used during the assessment as a backup. The focus group were of the opinion that this could lead to general advantages, for example, that the need to memorise technical detail would now be curtailed, because students would have access to textbooks containing the relevant information. They indicated that increased accessibility to detail may improve the quality of answers, and students could expand their answers to include forgotten facts, formulae and complex definitions.

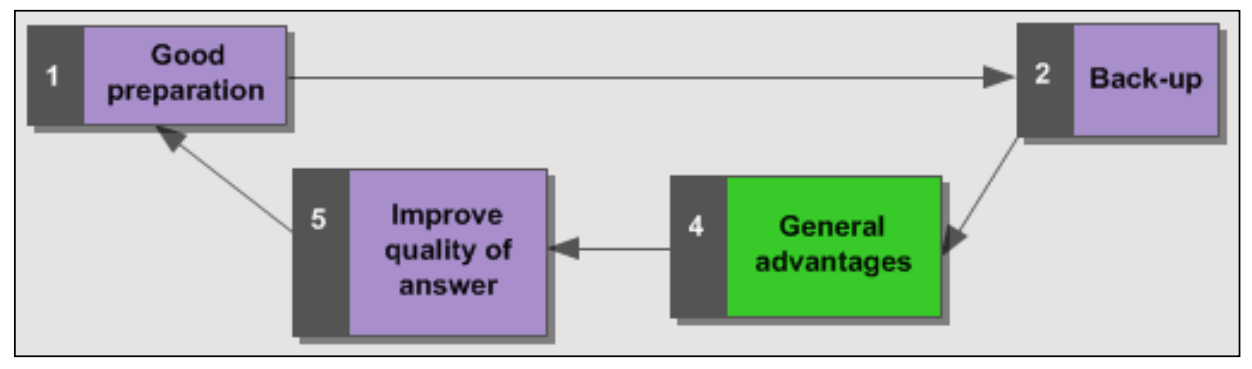

Diagram 3: Focus group - Feedback loop 1: More successful answers

The second feedback loop (Diagram 4) is named: Creating self confidence. This loop also starts with good preparation. The focus group believed that open-book assessment could create a feeling of encouragement to boost their confidence in their own abilities, brought about by the accessibility of resources. The focus group also indicated that open-book assessment appeared to have a motivational effect when the assessment was attempted. They said this resulted in an improvement in the quality of answers. The participants believed that the more success students had in open-book assessment, the more encouraged they would feel about preparing for the assessment, after which the feedback loop would start again from the beginning. 


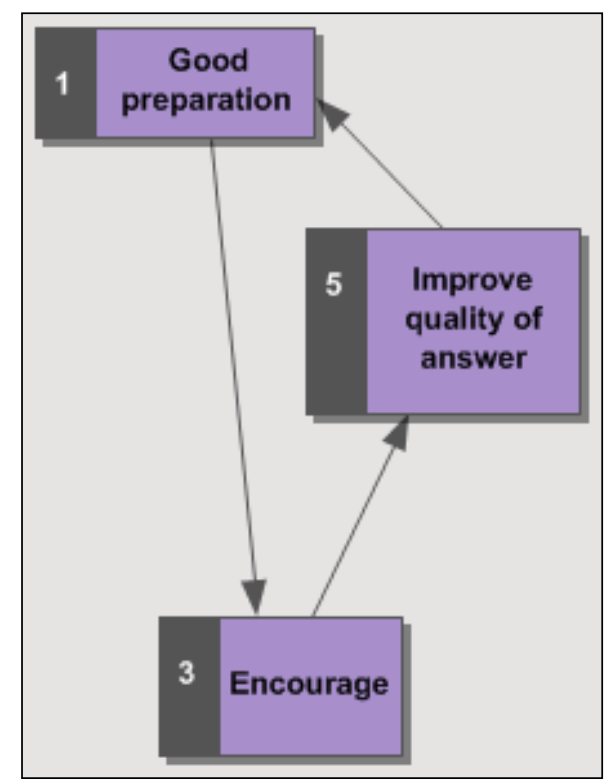

Diagram 4: Focus group -Feedback loop 2: Creating self confidence

Apart from the two feedback loops, other affinities also influenced each other. The focus group felt that having a back-up available during the assessment led to more controlled time management before and during the assessment. They also maintained that the availability of a back-up called for a different approach to the mental and emotional preparation for the assessment, as well as an adjustment to the examination technique.

According to the focus group, the general advantage of having access to resources might also lead to negative symptoms in open-book assessment. These symptoms related to the time-consuming nature of preparation for open-book assessment and reluctance on the part of the students to prepare thoroughly on account of the ready availability of answers in the resources taken into the assessment venue.

The focus group noted that good preparation could also lead to a negative environment. They indicated that preparing the resources for the open-book assessment may lead to excessive paging through textbooks during the assessment, leading in turn to disruption in the assessment venue. This could result in a negative personal experience and could even be described as a personal hindrance. They understood this personal hindrance to be either unnecessary checking of the textbooks and notes because of the different approach, or waste of time on account of unsatisfactory time management.

\section{CONCLUSION}

The value of this study lies in creating a better understanding of open-book assessment, specifically in relation to Taxation students' perceptions. In conclusion, the findings indicated that students perceive good preparation as the strongest driver for successful completion of an open-book assessment. The SID pointed to three primary outcomes 
namely negative symptoms, different approach and time management. This implies that students perceived that open-book assessment may create laziness (negative symptom) in students before an assessment. The students anticipated that an open-book assessment would lead to a different approach when preparing and completing such assessments. Finally, they concluded that successful completion of an open-book assessment necessitates proper time management.

This is not a study that can be extrapolated to the general population; it only pertains to a specific group of students' perceptions on open-book assessment prior to experiencing open-book assessment. The IQA focus group method is mainly a theory generating method portraying the voice of a specific group about a specific phenomenon. For this study IQA was used as research methodology to create a better understanding of certain aspects of the phenomenon 'open-book assessment'. It also poses a possible model and theory on open-book assessment that may be further explored, scrutinised and researched. The findings of this study were expanded in a follow-up study where the affinities, as identified by the focus group, were commented on by interviewees that had experience of open-book assessment in the QE Part 1 (Du Preez, 2011).

Many of the constructs and concepts mentioned in this study can be connected and triangulated with other research. However, the following concepts and constructs did not emerge from this study:

- $\quad$ open-book assessment nurtures more creative answers and problem-solving in students (Jackson et al.,2006; SohLoi \& Yaun, 1998; Theophilides \& KoutseliniIoannidou, 2000);

- open-book assessment appears to simulate real-life assessment options (Boniface, 1985; Broyles et al., 2005; Feller, 1994; Francis, 1982; Heijne-Penninga et al., 2006); and

- $\quad$ open-book assessment enhances self-regulated learning (Brightwell et al., 2004; Theophilides \& Dionysiou, 1996) and self-monitoring on where and how to apply specific skills (Shepard, 2000).

In a more practical sense, the findings of this study could be applied to maximising the current preparation and assessment of taxation students before they write the QE Part 1. Eilertsen and Valdermo (2000) found that students need guidance when they are expected to change certain study habits. The introduction of open-book assessment makes such a change necessary. Assistance could be given via workshops, discussion groups, multimedia programmes, mentorship programmes, debriefing, consultation, focused social networking, simulated and 'real-life' assessments, awareness programmes and/or could even be built into their curriculum.

\section{REFERENCES}

Baillie, C. and Toohey, S. (1997). The "power test": Its impact on student learning in a material science course for engineering students. Assessment \& Evaluation in Higher Education, 22(1): 33-48.

Birenbaum, M. and Feldman, R.A. (1998). Relationship between learning patterns and attitudes towards two assessment formats. Educational Research, 40(1): 90-98. 
Boniface, D. (1985). Candidates' use of notes and textbooks during an open-book examination. Educational Research, 27(3): 201-209.

Botha, L., Fourie, N. and Geyser, H. (2005). Teaching, learning and assessment in large classes - a reality of educational change. Education as Change, 9(1): 60-79.

Bowman, R.A.J. (1994). Taxation - Examination technique. Executive Accounting London, 21(3): 8.

Brightwell, R., Daniel, J. and Stewart, A. (2004). Evaluation: Is an open book examination easier? Bioscience Education E-Journal, 3 May.

Broyles, I.L., Cyr, P.R. and Korsen, N. (2005). Open book tests: Assessment of academic learning in clerkship. Medical Teacher, 27(5): 456-462.

Chalmers, D. and Fuller,R. (1996). Teaching for learning at University. Kogan Page, London.

Clift, J.C. and Imrie, B.W. (1981). Assessing students, appraising teaching. Croom Helm, London.

Cooper, D.R. and Schindler, P.S. (2003). Business research methods. International 8th edition. Boston: McGrau Hill.

Creswell, J.W. (2003). Research design: Qualitative, quantitative, and mixed methods approaches. 2nd edition. California: Sage.

Du Preez, H. (2011). Interactive Qualitative Analysis of taxation students' perceptions of open-book assessment. SAAA International Conference, George, 26-29 June 2011.

Durham, K. (1990). The open book examination. Foundation for Education, Science and Technology, 24(4): 59.

Eilertsen, T.V. and Valdermo, O. (2000). Open-book assessment: A contribution to improved learning? Studies in Educational Evaluation, 26(2): 91-103.

Feldhusen, J.F. (1961). An evaluation of college students' reactions to open-book examination. Educational and Psychological Measurement, 21: 637-645.

Feller, M. (1994). Open-book testing and education for the future. Studies in Educational Evaluation, 20(2): 235-238.

Francis, J. (1982). A case for open-book examinations. Educational Review, 34(1): 1326.

Gray, T. (1993). Open book examinations. The New Academic, 3(1): 6-9.

Heijne-Penninga, M., Kuks, J. B. M., Schonrock-Adema, J., Snijders, T. A. B. and Cohen-Schotanus, J. (2006). Open-book tests to Complement assessment-programmes: Analysis of Open and closed-book tests. Advances in Health Sciences Education, 13: 263-273. 
Jackson, M., Watty, K., Yu, L. and Lowe, L. (2006). Final report to the Carrick institute for learning and teaching in Higher Education 2006: Assessing students unfamiliar with assessment practices in Australian Universities. Strawberry Hills: The Carrick institute for learning and teaching in Higher Education.

Jacobs, G.J. (1990). Die tydsfaktor, oopboekpraktyke en slaagsyfers in evaluering. Bulletin vir Dosente, 22(1): 1-9.

Kalish, R.A. (1958). An experimental evaluation of the open-book examination. Journal of Educational Psychology, 49: 220 - 240.

Killen, R. and Hattingh, A. (2004). Measuring the quality of student learning in outcomes-based education, South African Journal of Higher Education, 18(1):72-86.

Koutselini-Ioannidou, M. (1997). Testing and life-long learning: open-book and closedbook examination in a university course. Studies in Educational Evaluation, 23(2): 131-139.

Lancaster, J. (2006). Open book assessment in a South African context: A work in progress. SAAA Conference, Sun City: South Africa, January 2006.

Lavey, W.G. (2006). Responses by the Federal Communications Commission to WorldCom's accounting fraud. Federal Communications Law Journal, June: 613-682.

Mampane, R. and Bouwer, C. (2011). The influence of township schools on the resilience of their learners. South African Journal of Education, 31: 114-126.

March, R. (1980). Should we discontinue classroom tests? An experimental study. The High School Journal, 63(7): 288-292.

Mohanan, K.P. (1997). Open book examinations: A report and a response to some recurrent concern. Tri-annual newsletter produced by the Centre for Development of Teaching and Learning, 1 (2).

Northcutt, N. and McCoy, D. (2004). Interactive qualitative analysis: A systems method for qualitative research. London: Sage Publications.

eHow Education. (2009). How to study for an Open-book Exam. Retrieved June 4, from: http://www.ehow.com/PrintArticle.html?id=9271.

SAICA. (2005). Education general information. http://www.saica.co.za/DisplayContent.asp?ContentPageID=401_..[Accessed 28 October 2010].

SAICA. (2009). Open book policy: Updated and approved by EDCO. Johannesburg: SAICA.

Shepard, L.A. (2000). The role of assessment in a learning culture. Educational Researcher, 29(7): 4-14. 
SohLoi, L and Yuan, W. (1998). Open-book examinations, SABRE Working Paper Series. Nanyang Technological University: 10-98.

Struyven, K., Dochy, F. And Janssens, S. (2002). Students' perceptions about assessment in higher education: A review. The Joint Northumbria/Earli SIG Assessment and Evaluation Conference, Newcastle, August 2002.

Theophilides, C. and Dionysiou, O. (1996). The major functions of the open-book examination at the university level: a factor analytic study. Studies in Educational Evaluation, 22(2): 157-170.

Theophilides, C. and Koutselini-Ionnidou, M. (2000). Study behaviour in the closedbook and the open-book examination: A comparative analysis. Education Research and Evaluation, 6(4): 379-395.

Thomas, C.B. (2002). Called to account, Time in partnership with CNN, June. http://www.time.com/time/business/article/0,8599,263006,00.html [Accessed 19 September 2010].

Van Tonder, A.H.D. (1988). Die oopboekeksamen as alternatiewe eksamineringsmetode. Bulletin vir Dosente, 20(1): 49-52.

Wadee, N. (2010). Changes in the accounting profession. Accountancy SA, April: 1213.

Weber, L.J., McBee, J.K. and Krebs, J.E. (1983). Take home tests: An experimental study. Research in Higher Education, 18(4): 473-483.

Wikipedia. (2010). Accounting scandals. http://en.wikipedia.org/wiki/Accounting_scandals [Accessed 24 August 2010]. 
Appendix 1:

Table 1: A sample Affinity Relationship Table showing only the first 10 affinity pairs

Below is a list of the affinities you are requested to consider. Please also refer to the list of affinity descriptions for completing the table below. Remember that an arrow can go either left or right, but not in both directions.

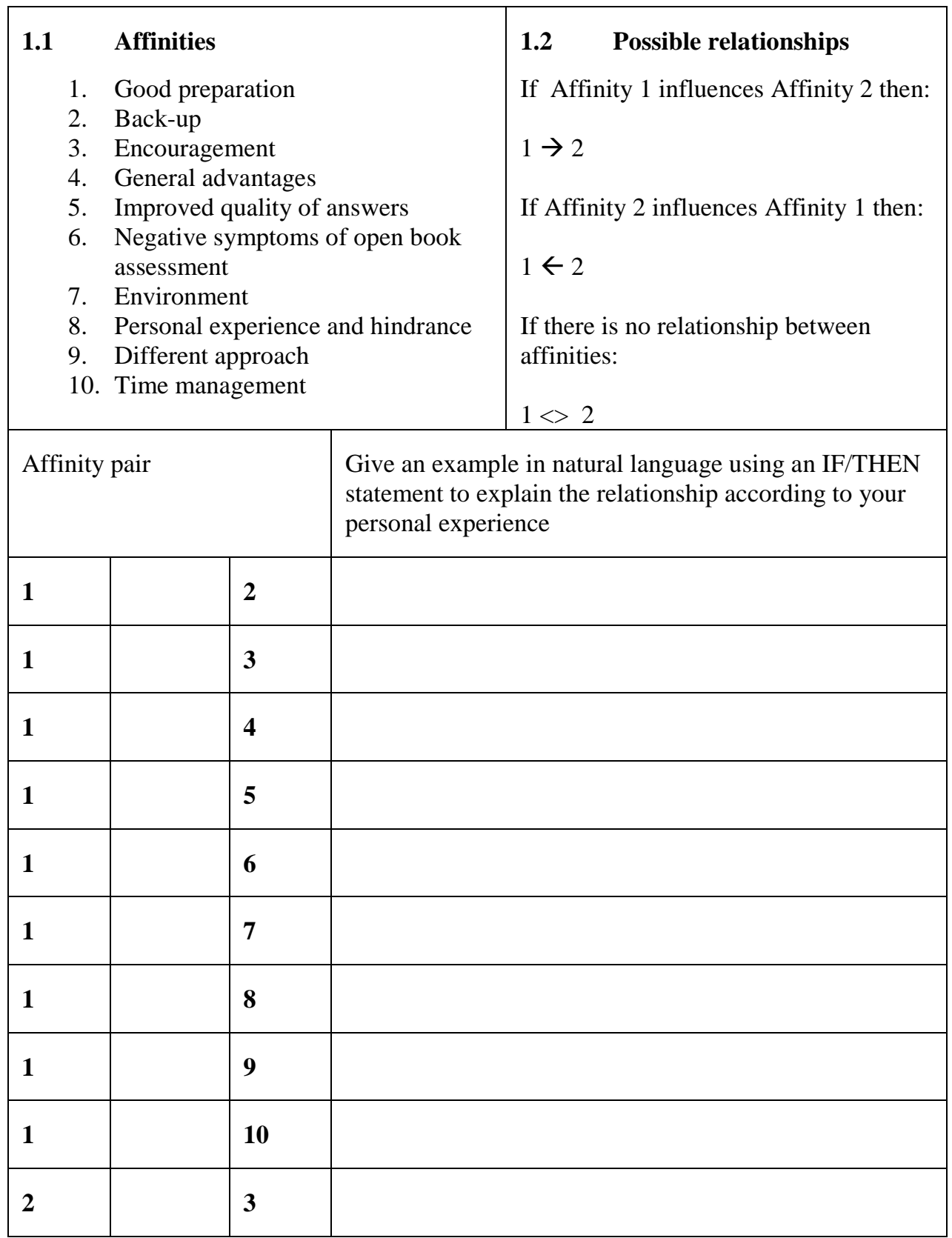




\section{Appendix 2:}

Table 2: Affinities in Descending Order of Frequency with Pareto protocol and Power analysis Table

\begin{tabular}{|c|c|c|c|c|c|c|}
\hline & $\begin{array}{c}\text { Affinity } \\
\text { pair } \\
\text { relationship }\end{array}$ & $\begin{array}{c}\text { Frequency } \\
\text { sorted } \\
\text { (descending) }\end{array}$ & $\begin{array}{l}\text { Cumulative } \\
\text { frequency }\end{array}$ & $\begin{array}{c}\text { Cumulative } \\
\text { per cent } \\
\text { (relation) }\end{array}$ & $\begin{array}{c}\text { Cumulative } \\
\text { per cent } \\
\text { (frequency) }\end{array}$ & Power \\
\hline 1 & $5 \rightarrow 6$ & 6 & 6 & 1.1 & 4.1 & 3.0 \\
\hline 2 & $1 \leftarrow 5$ & 5 & 11 & 2.2 & 7.6 & 5.4 \\
\hline 3 & $1 \rightarrow 6$ & 5 & 16 & 3.3 & 11.0 & 7.7 \\
\hline 4 & $1 \rightarrow 10$ & 5 & 21 & 4.4 & 14.5 & 10.0 \\
\hline 5 & $2 \rightarrow 10$ & 5 & 26 & 5.6 & 17.9 & 12.4 \\
\hline 6 & $3 \rightarrow 4$ & 5 & 31 & 6.7 & 21.4 & 14.7 \\
\hline 7 & $4 \rightarrow 6$ & 5 & 36 & 7.8 & 24.8 & 17.0 \\
\hline 8 & $7 \rightarrow 9$ & 5 & 41 & 8.9 & 28.3 & 19.4 \\
\hline 9 & $8 \rightarrow 9$ & 5 & 46 & 10.0 & 31.7 & 21.7 \\
\hline 10 & $8 \rightarrow 10$ & 5 & 51 & 11.1 & 35.2 & 24.1 \\
\hline 11 & $1 \rightarrow 3$ & 4 & 55 & 12.2 & 37.9 & 25.7 \\
\hline 12 & $1 \rightarrow 4$ & 4 & 59 & 13.3 & 40.7 & 27.4 \\
\hline 13 & $1 \rightarrow 7$ & 4 & 63 & 14.4 & 43.4 & 29.0 \\
\hline 14 & $1 \rightarrow 8$ & 4 & 67 & 15.6 & 46.2 & 30.7 \\
\hline 15 & $3 \rightarrow 5$ & 4 & 71 & 16.7 & 49.0 & 32.3 \\
\hline 16 & $5 \rightarrow 10$ & 4 & 75 & 17.8 & 51.7 & 33.9 \\
\hline 17 & $7 \rightarrow 10$ & 4 & 79 & 18.9 & 54.5 & 35.6 \\
\hline 18 & $1 \rightarrow 2$ & 3 & 82 & 20.0 & 56.6 & 36.6 \\
\hline 19 & $1 \rightarrow 9$ & 3 & 85 & 21.1 & 58.6 & 37.5 \\
\hline 20 & $2 \rightarrow 4$ & 3 & 88 & 22.2 & 60.7 & 38.5 \\
\hline 21 & $2 \rightarrow 9$ & 3 & 91 & 23.3 & 62.8 & 39.4 \\
\hline 22 & $3 \rightarrow 6$ & 3 & 94 & 24.4 & 64.8 & 40.4 \\
\hline 23 & $4 \leftarrow 5$ & 3 & 97 & 25.6 & 66.9 & 41.3 \\
\hline 24 & $2 \rightarrow 3$ & 2 & 99 & 26.7 & 68.3 & 41.6 \\
\hline 25 & $2 \rightarrow 5$ & 2 & 101 & 27.8 & 69.7 & 41.9 \\
\hline 26 & $2 \rightarrow 6$ & 2 & 103 & 28.9 & 71.0 & 42.1 \\
\hline 27 & $2 \rightarrow 7$ & 2 & 105 & 30.0 & 72.4 & 42.4 \\
\hline 28 & $2 \rightarrow 8$ & 2 & 107 & 31.1 & 73.8 & 42.7 \\
\hline 29 & $3 \rightarrow 10$ & 2 & 109 & 32.2 & 75.2 & 43.0 \\
\hline 30 & $4 \rightarrow 5$ & 2 & 111 & 33.3 & 76.6 & 43.2 \\
\hline 31 & $4 \rightarrow 10$ & 2 & 113 & 34.4 & 77.9 & 43.5 \\
\hline 32 & $6 \leftarrow 10$ & 2 & 115 & 35.6 & 79.3 & 43.8 \\
\hline
\end{tabular}




\begin{tabular}{|c|c|c|c|c|c|c|}
\hline 33 & $7 \rightarrow 8$ & 2 & 117 & 36.7 & 80.7 & 44.0 \\
\hline 34 & $7 \leftarrow 8$ & 2 & 119 & 37.8 & 82.1 & 44.3 \\
\hline 35 & $9 \rightarrow 10$ & 2 & 121 & 38.9 & 83.4 & 44.6 \\
\hline 36 & $1 \leftarrow 3$ & 1 & 122 & 40.0 & 84.1 & 44.1 \\
\hline 37 & $1 \leftarrow 4$ & 1 & 123 & 41.1 & 84.8 & 43.7 \\
\hline 38 & $1 \leftarrow 6$ & 1 & 124 & 42.2 & 85.5 & 43.3 \\
\hline 39 & $1 \leftarrow 10$ & 1 & 125 & 43.3 & 86.2 & 42.9 \\
\hline 40 & $2 \leftarrow 5$ & 1 & 126 & 44.4 & 86.9 & 42.5 \\
\hline 41 & $3 \leftarrow 4$ & 1 & 127 & 45.6 & 87.6 & 42.0 \\
\hline 42 & $3 \leftarrow 5$ & 1 & 128 & 46.7 & 88.3 & 41.6 \\
\hline 43 & $3 \rightarrow 7$ & 1 & 129 & 47.8 & 89.0 & 41.2 \\
\hline 44 & $3 \leftarrow 8$ & 1 & 130 & 48.9 & 89.7 & 40.8 \\
\hline 45 & $3 \rightarrow 9$ & 1 & 131 & 50.0 & 90.3 & 40.3 \\
\hline 46 & $3 \leftarrow 9$ & 1 & 132 & 51.1 & 91.0 & 39.9 \\
\hline 47 & $3 \leftarrow 10$ & 1 & 133 & 52.2 & 91.7 & 39.5 \\
\hline 48 & $4 \leftarrow 7$ & 1 & 134 & 53.3 & 92.4 & 39.1 \\
\hline 49 & $4 \leftarrow 8$ & 1 & 135 & 54.4 & 93.1 & 38.7 \\
\hline 50 & $5 \rightarrow 7$ & 1 & 136 & 55.6 & 93.8 & 38.2 \\
\hline 51 & $5 \leftarrow 8$ & 1 & 137 & 56.7 & 94.5 & 37.8 \\
\hline 52 & $5 \leftarrow 9$ & 1 & 138 & 57.8 & 95.2 & 37.4 \\
\hline 53 & $5 \leftarrow 10$ & 1 & 139 & 58.9 & 95.9 & 37.0 \\
\hline 54 & $6 \leftarrow 7$ & 1 & 140 & 60.0 & 96.6 & 36.6 \\
\hline 55 & $6 \leftarrow 8$ & 1 & 141 & 61.1 & 97.2 & 36.1 \\
\hline 56 & $6 \leftarrow 9$ & 1 & 142 & 62.2 & 97.9 & 35.7 \\
\hline 57 & $6 \rightarrow 10$ & 1 & 143 & 63.3 & 98.6 & 35.3 \\
\hline 58 & $7 \leftarrow 10$ & 1 & 144 & 64.4 & 99.3 & 34.9 \\
\hline 59 & $9 \leftarrow 10$ & 1 & 145 & 65.6 & 100.0 & 34.4 \\
\hline 60 & $1 \leftarrow 2$ & 0 & 145 & 66.7 & 100.0 & 33.3 \\
\hline 61 & $1 \rightarrow 5$ & 0 & 145 & 67.8 & 100.0 & 32.2 \\
\hline 62 & $1 \leftarrow 7$ & $\mathbf{0}$ & 145 & 68.9 & 100.0 & 31.1 \\
\hline 63 & $1 \leftarrow 8$ & 0 & 145 & 70.0 & 100.0 & 30.0 \\
\hline 64 & $1 \leftarrow 9$ & 0 & 145 & 71.1 & 100.0 & 28.9 \\
\hline 65 & $2 \leftarrow 3$ & 0 & 145 & 72.2 & 100.0 & 27.8 \\
\hline 66 & $2 \leftarrow 4$ & 0 & 145 & 73.3 & 100.0 & 26.7 \\
\hline 67 & $2 \leftarrow 6$ & 0 & 145 & 74.4 & 100.0 & 25.6 \\
\hline 68 & $2 \leftarrow 7$ & 0 & 145 & 75.6 & 100.0 & 24.4 \\
\hline 69 & $2 \leftarrow 8$ & 0 & 145 & 76.7 & 100.0 & 23.3 \\
\hline 70 & $2 \leftarrow 9$ & 0 & 145 & 77.8 & 100.0 & 22.2 \\
\hline
\end{tabular}




\begin{tabular}{|l|l|l|l|l|l|l|}
\hline $\mathbf{7 1}$ & $2 \leftarrow 10$ & $\mathbf{0}$ & 145 & 78.9 & 100.0 & 21.1 \\
\hline $\mathbf{7 2}$ & $3 \leftarrow 6$ & $\mathbf{0}$ & 145 & 80.0 & 100.0 & 20.0 \\
\hline $\mathbf{7 3}$ & $3 \leftarrow 7$ & $\mathbf{0}$ & 145 & 81.1 & 100.0 & 18.9 \\
\hline $\mathbf{7 4}$ & $3 \rightarrow 8$ & $\mathbf{0}$ & 145 & 82.2 & 100.0 & 17.8 \\
\hline $\mathbf{7 5}$ & $4 \leftarrow 6$ & $\mathbf{0}$ & 145 & 83.3 & 100.0 & 16.7 \\
\hline $\mathbf{7 6}$ & $4 \rightarrow 7$ & $\mathbf{0}$ & 145 & 84.4 & 100.0 & 15.6 \\
\hline $\mathbf{7 7}$ & $4 \rightarrow 8$ & $\mathbf{0}$ & 145 & 85.6 & 100.0 & 14.4 \\
\hline $\mathbf{7 8}$ & $4 \rightarrow 9$ & $\mathbf{0}$ & 145 & 86.7 & 100.0 & 13.3 \\
\hline $\mathbf{7 9}$ & $4 \leftarrow 9$ & $\mathbf{0}$ & 145 & 87.8 & 100.0 & 12.2 \\
\hline $\mathbf{8 0}$ & $4 \leftarrow 10$ & $\mathbf{0}$ & 145 & 88.9 & 100.0 & 11.1 \\
\hline $\mathbf{8 1}$ & $5 \leftarrow 6$ & $\mathbf{0}$ & 145 & 90.0 & 100.0 & 10.0 \\
\hline $\mathbf{8 2}$ & $5 \leftarrow 7$ & $\mathbf{0}$ & 145 & 91.1 & 100.0 & 8.9 \\
\hline $\mathbf{8 3}$ & $5 \rightarrow 8$ & $\mathbf{0}$ & 145 & 92.2 & 100.0 & 7.8 \\
\hline $\mathbf{8 4}$ & $5 \rightarrow 9$ & $\mathbf{0}$ & 145 & 93.3 & 100.0 & 6.7 \\
\hline $\mathbf{8 5}$ & $6 \rightarrow 7$ & $\mathbf{0}$ & 145 & 94.4 & 100.0 & 5.6 \\
\hline $\mathbf{8 6}$ & $6 \rightarrow 8$ & $\mathbf{0}$ & 145 & 95.6 & 100.0 & 4.4 \\
\hline $\mathbf{8 7}$ & $6 \rightarrow 9$ & $\mathbf{0}$ & 145 & 96.7 & 100.0 & 3.3 \\
\hline $\mathbf{8 8}$ & $7 \leftarrow 9$ & $\mathbf{0}$ & 145 & 97.8 & 100.0 & 2.2 \\
\hline $\mathbf{8 9}$ & $8 \leftarrow 9$ & $\mathbf{0}$ & 145 & 98.9 & 100.0 & 1.1 \\
\hline $\mathbf{9 0}$ & $8 \leftarrow 10$ & $\mathbf{0}$ & 145 & 100.0 & 100.0 & 0.0 \\
\hline & & $\mathbf{1 4 5}$ & & & & \\
\cline { 2 - 7 } & & & & & & \\
\hline
\end{tabular}




\section{Appendix 3:}

Table 3: Tabular IRD for the focus group: Sorted in descending order of $\Delta$

\begin{tabular}{|c|c|c|c|c|c|c|c|c|c|c||c|c|c|}
\hline $\boldsymbol{*}$ & $\mathbf{1}$ & $\mathbf{2}$ & $\mathbf{3}$ & $\mathbf{4}$ & $\mathbf{5}$ & $\mathbf{6}$ & $\mathbf{7}$ & $\mathbf{8}$ & $\mathbf{9}$ & $\mathbf{1 0}$ & Out & In & $\Delta$ \\
\hline $\mathbf{1}$ & & $\uparrow$ & $\uparrow$ & $\uparrow$ & $\leftarrow$ & $\uparrow$ & $\uparrow$ & $\uparrow$ & $\uparrow$ & $\uparrow$ & 8 & 1 & 7 \\
\hline $\mathbf{5}$ & $\uparrow$ & & $\leftarrow$ & $\uparrow$ & & $\uparrow$ & & & & $\uparrow$ & 4 & 1 & 3 \\
\hline $\mathbf{2}$ & $\leftarrow$ & & & $\uparrow$ & & & & & $\uparrow$ & $\uparrow$ & 3 & 1 & 2 \\
\hline $\mathbf{3}$ & $\leftarrow$ & & & $\uparrow$ & $\uparrow$ & $\uparrow$ & & & & & 3 & 1 & 2 \\
\hline $\mathbf{7}$ & $\leftarrow$ & & & & & & & $\uparrow$ & $\uparrow$ & $\uparrow$ & 3 & 1 & 2 \\
\hline $\mathbf{8}$ & $\leftarrow$ & & & & & & $\leftarrow$ & & $\uparrow$ & $\uparrow$ & 2 & 2 & 0 \\
\hline $\mathbf{4}$ & $\leftarrow$ & $\leftarrow$ & $\leftarrow$ & & $\leftarrow$ & $\uparrow$ & & & & & 1 & 4 & -3 \\
\hline $\mathbf{6}$ & $\leftarrow$ & & $\leftarrow$ & $\leftarrow$ & $\leftarrow$ & & & & & & 0 & 4 & -4 \\
\hline $\mathbf{9}$ & $\leftarrow$ & $\leftarrow$ & & & & & $\leftarrow$ & $\leftarrow$ & & & 0 & 4 & -4 \\
\hline $\mathbf{1 0}$ & $\leftarrow$ & $\leftarrow$ & & & $\leftarrow$ & & $\leftarrow$ & $\leftarrow$ & & & 0 & 5 & -5 \\
\hline
\end{tabular}

*Affinities: 1-Good preparation, 2-Back-up, 3-Encouragement, 4-General advantages, 5Improved quality of answers,

6-Negative symptoms, 7-Environment, 8-Personal experience and hindrance, 9-Different approach, 10-Time management 